\title{
The politics of performative ontology in information systems
}

\author{
$\operatorname{DPOSTMA} A^{1}$
}

\begin{abstract}
This article argues that information systems (ISs) and information system ontologies (ISOs) are powerful devices that perform reality in profound ways. The development and use of ISOs are forms of ontological politics through which interests are promoted, identities established and resources distributed. ISOs are ideological in so far as their political nature is not recognised while serving partial interests. This happens when ISOs are seen as merely technical, inevitable and natural. A democratic politics of ISs and ISOs is needed in order to make public these political actions. This article aims to create a critical awareness of the ways in which technologies perform reality an $\mathrm{d}$ argues that the political agenda must be activated through the opening up of terrains of dissensus and contestation within the technical performances of reality. It provides examples of such ontological politics of technology.
\end{abstract}

Keywords: Information system ontologies, performativity, technology, politics, contestation

\section{Introduction}

Technology in general and information technology in particular shape reality profoundly. From this perspective, The Anthropocene ${ }^{2}$ (Crutzen \& Stoermer, 2000) does not simply refer, as the name suggests, to the dominant role of only humans, but rather to the powerful effects of assemblages of which humans are a part and within which they do not necessarily have the first or last say. This is illustrated by and understanding that the unprecedented impact humans have on and beyond planet earth would not be possible without technologies. Human abilities to penetrate to the invisible nano-terrain and to explore expanding horizons of outer space and to leave an indelible trace everywhere are mediated and made possible by technologies. In these processes technologies are not simply instruments (intermediaries) through which predefined purposes are achieved but they play an active role as mediators to co-define these purposes (Latour, 2002). How we define and experience values, humanity, health, death or work, change through the participation of technologies. Technologies are not something that we act on or with, but they have become co-actors that change ends and conceptions of what is good.

${ }^{1}$. Dr. Dirk Postma at attached to the University of Johannesburg. Email: dpostma@uj.ac.za

$2 \mathrm{http} / /$ www.anthropocene.info/en/home

TD The Journal for Transdisciplinary Research in Southern Africa, 9(2) December 2013, pp. 206-224. 
The exponential growth of information technology (IT) refers to the expansion and intensification of its reach and effect. This intensification and durability of technology gain momentum through the development of information systems (ISs) which draw various technologies together to organise, control and survey people, things and processes (Berg, 1999). The fluid globality has created the need to develop ways to translate concepts and taxonomies between ISs through the development of ontologies within information systems, information system ontologies (ISOs).

The article argues that technology is not a neutral device simply in the service of efficiency, but a political agent which participates in the promotion of interests, the creation of identities and the distribution of resources. In order to recognise this political role, it has to be realised that politics does not simply refer to the actions of voters and politicians, but to the subtle and profound ways in which social reality itself is shaped. Politics is not limited to human interactions through which interests are negotiated, but it extends to the inscription of particular categories, interests and relations within reality, giving it an enduring material existence.

Political awareness of the role of technologies is necessitated by the powerful ways in which technologies contribute to the irreversible (Callon \& Latour, 1981, p. 301) and immobility (Law, 1986, p. 241) of the categories and identities as testified to in the following statement:

The information sciences have this century grappled with new ways of configuring, storing and retrieving information, as fundamentally novel as was the printing press in its day.... This new infrastructure has powerful ramifications, comparable to the railroads .... or electricity ... infrastructures that respectively accompanied the first industrial revolution and drove the second. Because new information infrastructures fundamentally change both work practice and knowledge, they also inscribe a moral order. They do so by allocating resources .... structuring markets ... and affecting the rhythm of daily life (Bowker, Timmermans, E' Star, 1996, p. 346).

This quotation suggests that ITs, ISs and ISOs play an active political role. Close attention should therefore be paid when these technologies shape the very nature of reality beyond their contribution towards human powers, efficiency and comforts. This article points towards this political role of technology and investigates how this could become more open and participatory.

This issue of the politics of technology has to be investigated in a transdisciplinary way. It is not just an interdisciplinary approach where different disciplines contribute their insights to the phenomenon. The transdisciplinarity comes to the fore in the ways disciplinary boundaries are transgressed by using theories and concepts developed within a particular discipline in the attempt to address in a holistic way an issue that does not fall within the terrain of any one discipline (Kroeze, 2012). This article contributes to transdisciplinarity by transgressing the disciplinary boundaries between political studies, gender studies, information systems, quantum physics, medical research, postcolonial studies and philosophy in an attempt to understand a particular phenomenon. It is shown how insights within one terrain could be used to illuminate issues within another.

The basic argument of this article is that ISs and ISOs should be seen as performative devices which organise and structure social reality in particular ways. Since ISOs has such political effects they should become part of overt political processes. One step towards bringing them 
into such processes is by creating an awareness of and by making public the effects of technological interventions.

The argument enfolds as follows: The development of ISOs is located against the background of philosophical ontology in order to identify the ontological assumptions within ISOs. In order to understand that ISOs have an effect on reality, realist and instrumentalist conceptions of the relation between ISOs and reality are contrasted with a performative conception of this relation. It is indicated that such performances are political and that technologies such as ISOs play an active political role. A notion of the political is developed in order to account for this political role and to see how technology could be brought into overt political interactions. It is argued by means of two examples that terrains of contestation and dissensus should be opened up in order to make public the particular political role played by technologies.

\section{Information System Ontology}

This section maps some of the ways ISOs are seen in the literature from the perspective of the relation between notions of ontology and reality. This provides the background for the following section which develops the argument that, however the relation between ISOs and reality is seen in the literature or in practice, ISOs perform reality in powerful ways.

It is firstly useful to make a number of distinctions that will be clarified and used in the rest of this section. Ontology is understood in this article in a philosophical sense as the study of the nature and structure of reality. Two conceptions of ontology could be distinguished: realist and instrumentalist (or pragmatist). Two kinds of realist views exist: objectivism and social constructivism $^{3}$. Two kinds of ontologies are also found: single and multiple. Although these analytical distinctions might not correspond to any particular philosophical ontology or an ISO they provide a framework to discuss and compare the different approaches. The dominant philosophical ontology originating from Plato is realist, objectivist and singular. It means that ontology describes a reality that exists independently of such description and that there is only one reality. An instrumentalist ontology does not claim that the concepts and categories correspond to an objective reality, but they simply help us to get along in the world. In a strong form the social constructivist ontology claims that reality is constructed through human concepts and categories. The notion of ontology as multiple will be addressed below.

The development of ISOs has become an important project within the development of information systems. The development of many different information systems led to the question about their relationship and about the transferability between them. Growing globalisation characterised by the shrinking of time and distance demands harmonisation and translatability between such systems in attempts to avoid fragmentation. The development of ISOs aims to address the bewildering plurality of information systems through the creation of a meta-language and set of categories which could act as a reference point for the translation of regional (domain specific) languages. Through conceptual modelling and the utilisation of appropriate categories, this meta-language promotes translatability and contributes towards harmonious information systems. 
Wand \& Weber $(1993,2004)$ set the tone for the development of ISOs by proposing a conceptual modelling of the world where there is a one-to-one relation between the ontological and the grammatical.

Why are theories of ontology relevant to the information systems field? The answer is that the essence of an information system is that it is intended to be a faithful representation of a world that a human or group of humans perceives (Wand E Weber, 2004).

They utilised philosophical ontology to assist with the classification and to promote the integrity of formal categories such as part-whole relations. Ontology also functions mainly as a taxonomy by means of which phenomena in the world could be classified. The assumption is that this classification could be done accurately and definitively. The ontology is based on the distinction between entities (things and properties), relations and processes.

The underlying conception of ontology is described by Smith (2003):

Ontology seeks to provide a definitive and exhaustive classification of entities in all spheres of being. The classification should be definitive in the sense that it can serve as an answer to such questions as: What classes of entities are needed for a complete description and explanation of all the goings-on in the universe? Or: What classes of entities are needed to give an account of what makes true all trutbs? It should be exhaustive in the sense that all types of entities should be included in the classification, including also the types of relations by which entities are tied together to form larger wholes.

Smith (2003) further explains his view as follows:

Another way of stating this point: it is precisely because good conceptualizations are transparent to reality that they have a reasonable chance of being integrated together in robust fashion into a single unitary ontological system. The fact that the real world itself plays a significant role in ensuring the unifiability of our separate ontologies thus implies that, if we are to accept a conceptualization-based methodology as one stepping stone towards the construction of adequate ontologies, then we must abandon the attitude of tolerance towards both good and bad conceptualizations. For it is this very tolerance which is fated to undermine the project of ontology itself.

When compared to the basis distinctions within philosophical ontology, one conception of ontology that transpires here is one that is objectivist, realist and singular. The assumptions are that there is a single reality which the ISO represents and that this representation could be done accurately. Further ontological assumptions are made such as the existence of clearly definitive natural kinds and a hierarchy of things in the world.

Smith (2003) reports further that the ideal of a unified ontology is not feasible anymore and the inevitability of domain-specific ontologies should be accepted. ISOs have now become a more modest field since it does not claim to represent reality as a whole, but only reality within a particular domain. The ideal is, however, still to standardise the domain-specific ontology (concepts, identities, categories and relations). In so far as these domain-specific ontologies are seen as realist, they accept the multiplicity of an objective reality. There are more than one domains which exist independent of our descriptions. The issue of the relation between the different domains remains a question once ontologies are multiplied. 
ISO developers and researchers have expressed the difficulties related to the attempts to represent an objective reality complete and accurately (Smith, 2003). This applies to both singular and multiple ontologies. One way in which this is resolved is to see ontology as a social construction. In this view no attempt is made to represent an objective reality, but only the reality as experienced and perceived by designers and users. This is particularly the case when ontology is seen as a form of conceptual modelling. According to this view the development of ISOs consists in establishing a correspondence between the ISO and the social reality as seen by the participants.

Whether single or multiple, the question of the relation between ISOs and reality could be answered in different ways. The singular realist view assumes that a single reality exists independently of our knowledge representations and that an ISO attempts to represent the world as it is as accurately as possible. When seen realistically multiple ontologies limit their representation to a particular domain and accept that another domain may have a different ontology. The larger question of a meta-ontology need not be asked since different realities exist next to each other. A social realist (or constructivist) view sees reality as that which corresponds to the perceptions and experiences of users and does not ask about an objective reality.

The relation between the ontology and reality is severed when the ISO is seen in an instrumental way as is sometimes the case with the notion of an ISO as a form of conceptual modelling of a domain. No ontological claims are made and the ontology is not seen as representing an objective or a social reality in any way. Ontology has now become a conceptual tool without any realistic value. Ontologies are nothing more than useful devices to map a particular conceptual terrain in order to ensure coherence and consistence of an information system. No reality is attributed to conceptual modelling and classification. Such an approach is present in the views of Wand \& Weber who emphasise the taxonomic function of an ISO and the fit between conceptual modelling and the perceptions of participants. The purpose is simply to improve the efficiency and effectiveness of an IS in relation to particular standards and expectations. This concern is mainly pragmatic since it aims at a workable solution of the looming crisis of incompatibility and incongruence. Smith (2003) calls this an internal metaphysics which is about 'a correct account of the taxonomical system use by speakers'.

This section started with a mapping of different kinds of (philosophical) ontologies. Although limited, the account of ISOs serves to show how they relate to the categories of philosophical ontology as far as the relation between ontology and reality is concerned. It is indicated that ISOs could be seen as realist, constructivist or instrumentalist and, if realist, they could represent reality as singular or as multiple. The mapping of ISOs in relation to philosophical ontology is valuable in relation to the way philosophical ontology is developed further in this article.

\section{From representation to performativity}

While realist and constructivist ontologies claim to represent reality in some way, instrumentalist ontologies do not claim any relation to reality since they aim at the more efficient functioning of an IS. In all these cases the ISOs are seen to be neutral. The neutrality of the first two lies in their claim to simply represent reality as it is. The neutrality of the instrumentalist view lies in its claim not to relate to reality in any way. 
In this section it is argued that the neutrality of the first two ontologies cannot be maintained when the relation between ontology and reality is not seen in terms of representation, but in terms of performativity. Since performativity also applies to a kind of ISO that sees itself in an instrumentalist way, its claim to neutrality can also not be maintained.

The central claim developed in this section is that however the relation between ISOs and reality is seen in the development and use of ISOs, reality is always being performed in particular ways. It is then argued in the next section that this performance of reality is not politically neutral.

The notion of performativity could be traced to Austin's (1962) view of language as action. In contrast to a view of language as representing reality, Austin argues that language performs reality. A statement by a marriage official that 'you are now married' does not attempt to describe a state of affairs, but it brings the state about. The notion of performativity has gained momentum within the context of gender studies where Butler (1993) argues that gender is not a naturally given characteristic of humans, but it is continually being performed. The reality of gender identity is performed through material and embodied actions such as clothing, walking and talking. Through such performances the reality of a gender identity is established.

This positive ${ }^{4}$ notion of the performativity (or enactment) of reality has obtained a material focus in Barad's (2007) reading of quantum physics. ${ }^{5}$ Barad (2007, p. 110 ff.) provides a perspective on how reality is enacted through her investigation of the wave/particle duality. She offers a particular interpretation of Bohr's views expressed in his debate with Heisenberg about the nature of reality. Heisenberg uses the concept 'complementarity' to refer to the way in which reality could be described in terms of both waves and particles and 'uncertainty' when referring to the status of epistemological claims about reality. In contrast to this Bohr typifies reality as 'indeterminate' and claims that it only becomes determinate through the intervention of an experimental apparatus. Bohr illustrates this point by means of a thought experiment of a particle fired towards a measuring device in order to establish its status. This status is constituted by both the position and momentum of the particle. The experiment illustrates that the status of the particle cannot be established since position and momentum could not be measured simultaneously. While the measurement of position is dependent on a fixed measuring instrument (such as a fixed platform), the measurement of momentum requires a movable measuring instrument. Barad concludes:

\section{Crucially, then, the position and momentum are not simultaneously determinate because they require mutually exclusive experimental circumstances. (Barad, 2007, p. 111)}

The status of the particle could only become determinate through either of the experimental apparatuses. What further complicates the relation between the measurement and a preexisting reality is the realisation that the measuring instrument interferes with the object that

\footnotetext{
${ }^{4}$ It has to be noted that the productive and constructive notion of performativity that is being developed here is different from the critical meaning originating from Lyotard (1984). Lyotard's conception has provided important insights into the nature of modernity and the role of managerialism (Fournier \& Grey, 2000; Grey \& Willmott, 2002). Other critical views have, however, drawn on the productive notion of performativity in the tradition of Butler (Alcadipani \& Hassard, 2010; Spicer, Alvesson \& Kärreman, 2009).

5 This appeal to science in an attempt to understand ontology is significant in the light of Smith's (2003) account of the role of science in the development of both philosophical and IS ontologies.
} 
is being measured and that the extent of this interference cannot be established. Barad emphasises that the measuring practice makes the measurement determinate. The measured position and momentum do not refer to the position or momentum of the object independent of the measuring instrument as is the case in Newtonian physics where 'objects have individually determinate properties before the act of measurement' (Barad, 2007, p. 111). Barad generalises this claim by stating that reality itself does not consist of determinate individual objects since

\section{we can't know something definite about something for which there is nothing definite to know (Barad, 2007, p. 118).}

Phenomena are not simply what appears in the human consciousness (as claimed in phenomenology), but they (objects, entities) become determinate through heterogeneous knowledge-making practices. The apparatuses in the thought experiment above contribute to making the status of the particle (position and momentum) determinate. This heterogeneous assemblage, consisting of humans, artefacts, procedures and apparatuses, participates in determining (or enacting) reality. Barad emphasises that this view represents a shift from Heisenberg's epistemology of uncertainty to Bohr's ontology of indeterminacy. While we are, according to Heisenberg, never certain whether our knowledge practices accurately reflect reality, according to the view of Bohr as presented by Barad, epistemological certainty and ontological determinacy could be achieved through heterogeneous practices.

From insights such as these Barad draws conclusions about Bohr's ontology: Reality itself is indeterminate and only becomes determinate through heterogeneous practices such as human/apparatus experiments. Such heterogeneous assemblages are agents through which reality is enacted (therefore her notion of 'agential realism'). The production of knowledge and the enactment of reality are relative to the particular heterogeneous assemblage. Knowledge does not correspond to an independently existing world, but it is the outcome of such knowledge practices through which this very reality is enacted. Knowledge practices do not reflect a pre-existing independent reality, but it participates in the very constitution of the reality. Reality does not consist of discrete entities which correspond to our concepts, to the contrary, through the knowledge- and reality-making practices we are able to render reality discrete and definable.

The particular way in which reality is made determinate relates to the ontological assumptions and commitments behind, or which emerge from, the heterogeneous practices. The ontological outcomes of such heterogeneous interventions are not the effects of prior ontological assumptions and commitments, but they are rather emergent effects of the heterogeneous assemblage.

This account of the way reality becomes (determinate) through heterogeneous assemblages has important implications for the way the relation between ISOs and reality is to be understood. ISOs are heterogeneous assemblages similar to the experimental apparatuses. Whereas the experimental setup consists of humans and apparatuses, ISOs consist of humans, systems of classification, conceptual modelling, computer software and hardware, etc. It could then be stated that ISOs are agents through which reality is performed in particular ways.

The relation between ISOs and reality could therefore not simply be seen in terms of ontological realism, social constructivism or instrumentalism. ISOs can not be seen as representing a pre-existing (objective or social) reality and they do not act neutrally as 
instruments within reality, but a particular reality emerges from an ISO. ISOs therefore do not represent reality, but intervene in the constitution of reality. ${ }^{6}$ The powerful and ubiquitous agency of technologies makes them a very strong determinant of a particular reality.

While IS and ISO researchers, developers and users may work with either realist or instrumentalist views of the relation between the ISO and reality, ISOs always perform reality in particular ways. Even though ISO developers may think that they simply use conceptual categories that correspond to their or to users' views of the world, they perform a reality that might or might not comprise the same ontological assumptions as those of the participants. Even though ISO developers and users may think that their concepts and categories correspond with a real underlying reality, they perform a particular reality that may or may not correspond to these concepts and categories.

It cannot be established beforehand which reality is being performed. This reality does not coincide with the ontological assumptions of the designers or the users. The notion that technology has agency suggests that the outcome may be unexpected and unintended. The agency of technology means that interests, intentions and purposes shift in unpredictable ways.

\section{The multiplicity of reality}

The argument so far is that that ISs and ISOs perform reality in particular ways. The fact that reality is performed is independent of participants' views of whether and how they affect or represent reality through the design and use of ISOs. It is argued in this section that the reality that is being performed is not singular, but multiple. ${ }^{7}$ If reality is performed by heterogeneous practices, then it is being performed differently through different such practices.

Such a notion of multiplicity is developed by Mol (2002) on the basis of her empirical philosophical investigation into medical practices. In line with the way reality is performed through heterogeneous assemblages as argued above, she shows how different (heterogeneous) diagnostic and treatment practices produce different realities of lower-limb atherosclerosis. It is an error to assume that, since one concept (atherosclerosis) is being used, there must be a single underlying reality. In contrast to such a notion of a singular reality, Mol describes how one reality of lower-limb atherosclerosis is performed in the consulting room, another in the pathology laboratory, another in the radiology department, another through an angiograph and still another reality in the operating theatre. The ontological reality of atherosclerosis varies on the basis of ways in which it is produced through different heterogeneous assemblages of people, apparatuses and processes.

The practices of clinical and pathological atherosclerosis exclude each other in the sense that they cannot be performed simultaneously. To take one example from Mol (p. 35), clinically in the outpatients section physicians talk to patients to establish whether their legs hurt as an indication of the existence of atherosclerosis. This is different from how the pathologist performs atherosclerosis under the microscope (as a heterogeneous assemblage):

\footnotetext{
${ }^{6}$ This contrast between representation and intervention is elaborated on by Hacking (1983) with reference to scientific practices.

7 This notion of reality is related to the shift from 'ontology' to 'ontologies' in ISOs.
}

TD, 9(2), December 2013, pp. 206-224. 
'Now there's your atherosclerosis. That's it. A thickening of the intima. That's really what it is'. And then he adds, after a little pause: 'Under a microscope' (Mol, 2002, p. 30).

The clinician does not need a microscope to diagnose besides the fact that it is not possible. Although the clinical and pathological practices often coincide, there are many cases where they do not. Pathology does not answer the question in the clinical situation of what kinds of interventions and prescriptions are required. The clinical diagnosis is done without the pathological one. Pathology could only do its work when a leg is amputated or the patient has died. The objects in clinical and pathological practices do not always map on to each other. Incompatibilities between the different performances happen when, for example, a patient did not complain of any pain or discomfort in the clinical context, but has died of calcified arteries that could only be seen in the pathology laboratory. Reality is enacted in different ways: in the clinical context atherosclerosis is pain when walking, in pathology it is a thick arterial vessel wall.

The multiplicity of practices lead to the multiplicity of objects enacted. When we work with a kind of ontology that assumes the singularity of reality, we would assume that a single object exists and that it could be approached by different knowledge practices. The object would be singular, but our practices or perspectives are diverse. In such cases we would harmonise and gloss over the perspectival differences even when objects contradict each other. In contrast to this, an ontology that is based on a notion of multiplicity would recognise that the differences are at times significant and that attempts to harmonise or suppress them may have farreaching consequences for some groups.

So what I am trying to relate is not that there are two, five, seventy variants of atherosclerosis, but that there is multiplicity. That as long as the practicalities of enacting a disease are kept unbracketed, out in the open, the varieties of 'atherosclerosis' multiply (Mol, 2002, p. 51).

These heterogeneous agents (such as diagnostic and treatment practices) perform reality in different ways which, in the medical field, results for Mol in a 'body multiple': We do not have only one body since 'the same' body could be different things once 'it' is worked on through different practices.

These different performances of atherosclerosis does not imply a relativistic fragmentation of realities since comparisons, translations and associations are always possible. There are at times overlaps between the different realities and at other times contradictions which prevent them from being added up to a single reality. There is not one reality as seen in the tradition of philosophical ontology, which we could adequately capture through our concepts and categories. Different realities are performed through different heterogeneous assemblages such as medical practices, experimental apparatuses or ISOs.

The arguments of Barad and Mol could be applied to ISOs. With Barad we can see that reality is performed through technologies such as ISOs. ISOs does not and cannot map a preexisting reality since it interferes with the object it wishes to represent. An ISO performs a particular kind of reality to the exclusion of other kinds of reality.

From Mol we gain insights into the variety of ISs and ISOs. The differences between various ISs or ISOs, that are often incompatible and conflictual, should not simply be traced to limited or partial understandings of reality, or to the role of divergent interests or conceptual frameworks. It should rather be traced to the nature of reality itself which only becomes 
determinate through heterogeneous practices such as ISOs. Reality becomes determinate in a particular way through a particular heterogeneous intervention. The version of reality is the outcome of different agents such as the ontological assumptions embedded in an ISO and the active role of the ISO itself.

This understanding, gained from Barad and Mol, of the ways in which reality is performed as multiple through different ISOs raises questions of a political nature: What is the relationship between the different performances of reality? Which of these performances are better and for whom? Who decides which performance should dominate? If some enactments of reality are more powerful than others, what are the implications for those others? If different ISOs perform reality differently how are identities and resources allocated differently? Who is allowed to be part of the world that is created and what place is allocated to the different entities?

\section{The politics of technology}

ISOs perform reality in ways that are political since they create identities and distribute resources in ways that usually benefit some more than others. This section discusses first the ideology of neutrality within ISOs and consequently surveys the literature on the political role of technology in general and ISOs in particular.

A conception of the political nature of technology is in sharp contrast to the way in which technology is seen as a neutral instrument in the service of certain purposes (Orlikowski \& Iacona, 2001). Latour (2002, p. 255) articulates this as follows:

The paradox of technology is that it is always praised for its functional utility, or always beld in contempt because of its irritating neutrality, although it has never ceased to introduce a history of enfoldings, detours, drifts, openings and translations that abolish the idea of function as much as that of neutrality. How dare we qualify as neutral the ontological drama of unexpected assemblages of entities which can pass, without a hitch, from zero to infinity?

The dominant assumption within the design and development of technologies such as ISOs is that they mainly contribute to the efficiency and effectiveness of organisations. As a consequence the extent to which technologies are implicated in forms of ontological engineering is not adequately realised. This presumption of neutrality is present however the relationship between an ontology and reality is seen. A realist ISO is seen to be neutral because it simply represents reality and an instrumentalist ISO is seen to be neutral because it simply promotes the ideas of the particular design or use.

Such presumptions within ISOs to be (politically) neutral is ideological. It denies how political effects are produced by ISOs and it hides this very denial.

These political effects are already present in the choice of an ontology (ontologies) within ISOs whether seen in a realist or instrumentalist way. Such choices are present within the particular concepts and categories that are being employed and the ways in which relationships are being defined. The presumption that these concepts and categories represent an objective reality hides the way in which they already constitute (perform) the very reality they claim to represent. The political role is furthermore present in the particular reality that is being performed.

The political role of technology is the focus of a significant body of research. The performance of reality is related to the underlying or emergent ontological assumptions and 
commitments. The political role of IT and the embedded or emergent ontologies is described by Bowker:

It is clear, in general, that as we create worlds of electronic information which reflect our political economy in all its contradictions, it should be no surprise if the policies that get read out of these worlds should help us shape the world in the image of that political economy - again in all its contradictions (Bowker, 2000, p. 660).

The comments from Winner relates to the well-known discussion of the low overpasses which prevented buses (carrying mainly African-Americans) to the beaches of Long Island.

The things we call "technologies" are ways of building order in our world. Many technical devices and systems important in everyday life contain possibilities for many different ways of ordering human activity. Consciously or unconsciously, deliberately or inadvertently, societies choose structures for technologies that influence how people are going to work, communicate, travel, consume, and so forth over a very long time (Winner, 1986, p. 5).

Barry (2001) comments on the political importance of the economic and technological harmonisation during the establishment of the European Union. He emphasises in particular the agential role of technologies that exceeds their design and specifications:

In its preoccupation with such conventionally 'political' actors, political science fails to recognise the political agency of scientific and technical materials. (p. 81)

What appears to be a technical matter can become a political event with unexpected ramifications and 'untechnocratizable consequences. (p. 82)

The mutuality of human and technological agency is also present in Bijker's (2006) discussion of a large number of cases to support his conclusion that "all technology is political and all politics is technological". He argues that a detailed study of technological projects reveals how they are informed by political considerations and how political decisions cannot be understood without a careful study of technologies.

The politics of technology has also been described by Berg $(1998,1999)$. In conceptualising the nature of technology, Berg engages intensively with social and technological determinist and sociotechnical views. He argues that the political role of technology could not simply be explained through either of these views. Social constructivist views locate politics in human interactions and see technologies in the role of realising and enhancing human purposes. Technological determinist views, on the other hand, attribute political agency to technology which operates in accordance with an intrinsic logic (such as technological rationality) and imposes this logic wherever it functions. Berg (1999) argues that the particular effects of technology could only be established empirically through a careful investigation of emergent processes, agents and purposes. He shows, for example, how recording technologies in medical care fulfils an 'accumulating' and 'coordinating' function. These functions are apparently neutral because the purposes and outcomes are not pre-determined. They fulfil, however, a political role because they also contribute towards increased surveillance and control, or towards democratic decentralisation of practices. They are, however, never neutral within the dynamism of practices because they are inevitably entangled within the political struggles between interests groups within any practice.

In a health information system the realities of 'psychiatrist', 'patient' and 'diagnostic' are being performed in a particular way (Bloomfield \& McLean, 1996). In the IS of a tertiary 
institution, one could trace how the realities of the 'researcher' and of the 'university' are being performed (Scott \& Wagner, 2003). These problematical entities did not exist in the same way before the implementation of the ISs and are clearly an effect thereof. The power of ISs ensures the highly irreversible inscription of identities and relations.

Closer to ISs and ISOs, Bowker (2000) illustrates how the designers of a database prefer simple categories and how the entrenchment of these categories structure the world as experienced.

There are certain kinds of plants, animals and systems which are charismatic. These in turn create a set of others, entities which are often just as important, but which are overlooked because they do not lead to spectacular science or good funding opportunities (G. C. Bowker, 2000, p. 655).

Thus the world that is explored scientifically becomes more and more closely tied to the world that can be represented by one's theories and in one's databases: and this world is ever more readily recognized as 'the real world' - especially when measures can be taken to save only entities which have been named and studied (Bowker, 2000, p. 659).

It is clear that a database is an agent that not only provides the categories according to which the world is understood, but it also contributes towards the enactment of a particular world. Bowker refers to the concept 'grooving' to point to the ways in which data structures of databases determine how the world is understood and enacted.

Hacking (2007) argues a similar point. He describes a 'looping effect' which happens when the classification interacts with the people classified. The category 'multiple personality' interacted with and performed people as belonging to the category with the result that a

wholly new kind of person came into being, the multiple, with a set of memories and a set of behaviours... (Hacking, 2007, p. 298).

One also finds in Hacking (2007, p. 288. 289) a description of the heterogeneous practices and elements through which classifications are effected, such as classification, people classified, institutions, knowledge and experts. This is similar to the heterogeneity of Bohr's human/apparatus assemblages or to ISOs.

Although not all these examples are taken from the field of ISOs, they show how ontological assumptions and commitments are embedded in and emerge from technologies. They also indicate how such technologies play an active role in the distribution of political effects. The implication is that ISOs have important implications for reality and could never be seen as a neutral description of the world or as merely efficient systems. This politics refers to the potentially problematical ways in which the categories agencies, identities and resources are identified and distributed.

\section{The politics of contestation}

Because of these diverse and powerful effects (agency) of technology, it is important to bring it explicitly into the political processes through which the common world is created. The need to make the active role of technology public is necessitated by the fact that technologies exert their power silently and clandestinely (Latour, 1994), which is described here as the ideology of neutrality.

The political role of technology, or the politics of things (Bennet, 2010; Latour, 2004a) is not acknowledged in the dominant theories of democracy where politics is seen as an exclusively 
human activity. A brief encounter with deliberative and radical views of democracy helps to show how the politics of technology draws on and goes beyond these humanistic theories of democracy. In the light of the political role of technology we need to reconceptualise democratic politics in such a way that the participation of nonhumans is recognised and made visible.

The importance of human-centred discourse, transparency and active participation is developed in the liberal deliberative democracy of theorists such as Habermas (1984) and Benhabib (1996). Democratic politics is an on-going process where legitimacy is based on the following of deliberative processes based on the principles of equality, open debate and the equal opportunity to raise issues and to shape the agenda of the discussion. It requires the establishment of a neutral public sphere and is governed by principles of rationality and neutrality where particularistic interests are overcome.

The notion of radical democracy as developed by Mouffe (1992) asserts the importance of active political participation in defining and pursuing a common good. It diverts from the liberal notion of democracy which equates it with the maximisation of individual liberties and the devaluation of a common good. Democracy is radicalised when the values of equality and liberty inform all spheres of life and when 'domination can be challenged everywhere' (Mouffe, 1992:238). The political is therefore extended to terrains such as the workplace, culture, entertainment and consumption. In this sense democracy is a way of life that pervades all spheres. Mouffe wants to see democracy functioning to challenge the multiple ways through which equality and freedom are denied.

The radicalised form of democracy presented by Mouffe represents an important development in political theory since it widens the functioning and scope of democracy. The liberal and radical theories of democracy remains, however, limited since they only recognise the active participation of humans in democratic processes. They do not recognise the presence and performative power of agents that are not human which shape the terrain of the political in profound ways. Barry (2001, p. 10) shows how the very constitution of a public sphere valued in the liberal view is already technically mediated. This point is also clearly illustrated by Suchman's (1994) discussion of the communicative assumptions embedded in the system developed by Winograd and Flores discussed below. It is only when the role of nonhumans is taken into account that the meaning of democracy could be radicalised further in terms of an ontological (Mol, 1999), or cosmological (Latour, 2004b) politics.

One way in which technology is democratised through a notion of participatory design (Howcroft \& Wilson, 1999) is important but still limited to the agential role of humans. In order to account for the active role of nonhumans, Latour (2004a) has developed heterogeneous democratic politics in terms of due process. This provides a framework for a cosmopolitics within which the issues of inclusivity and stability are accounted for. For the purpose of this discussion and to illustrate how the role of technology could be made public, the view of Barry (2001) is drawn upon. Barry fully acknowledges the active role of technologies combined with human responsibility. For Barry technology is mainly an antipolitical instrument because it reduces controversy and displaces decision to technical bodies and experts such as the processes of standardisation within the European Union. It is therefore important for Barry that the terrain of the political be activated. In contrast to a definition of politics in terms of the struggle between institutions, political interests and ideologies (p.33), the political is the expanded terrain of participation that radical democracy has opened up. One issue that Barry identifies is that it is often not possible to trace the 
origin of important decisions. Such decisions are usually deeply embedded in technical details to such an extent that they are rendered 'non-decisions'. Important decisions are often not consciously and explicitly made, but deferred to technical processes and regarded as technical matters. On the basis of his understanding of ontological politics that is deeply embedded within the structure of ITs and the ways in which everyday reality is profoundly affected, Barry (2001) defines the political as the opening up of terrains of contestation. These 'nondecisions' have to be made explicit because they shape reality profoundly in a hidden way. The terrain of the political that has to be opened up consists inevitably of dissensus and contestation (Barry, 2001, p. 207). This terrain is defined as 'an index of space of contestation and dissensus' (Barry, 2001, p. 7). What has become deeply embedded in technologies has to be made explicit so that the particular way in which decisions were taken and realities performed, could be made explicit.

Barry's comments about ISs could be applied to the way in which significant decisions are embedded in ISOs. ISOs contribute to the establishment of a certain hegemony, understood in Gramscian (2007) terms as the dominance and general acceptance of particularistic interests and ideas of the dominant class. Mouffe's project of radical democracy is now extended to include nonhuman agents. The ways in which reality-performing agencies are embedded within technologies and simultaneously made invisible, should be opened up as terrains of contestation. One way of opening up such contestations is to trace the timing and location of such 'non-decisions' in processes such as conceptual modelling or ontological categorisation. Within the context of the powerful ontological and political role of technology, it is important that the terrain of the political be established.

\section{Opening up terrains of contestation}

Two examples closely related to ISOs are discussed of ways in which terrains of contestation could be opened up. One is a case of categorisation in an IS and the other the design of a database.

In her article Do categories have politics?, Suchman (1994) argues that the categories that Winograd \& Flores (1987) used in the design of COORDINATOR determined what could be said as part of the attempt to control speech in an organisation. Winograd and Flores draw on speech act theory where language is seen as a form of action. From this they devised a formal system of categorisation that aimed to guide the proper and efficient use of language in an organisation. Particular intentional categories are used to assist language users to make their intentions clear and their actions more successful.

Suchman (1994) states that a particular ontology is created where organisational life consists of speech acts. She comments about the political effects of these particular categories:

That is to say, systems of categorization are ordering devices, used to organize the persons, settings, events or activities by whom they are employed or to which they refer. Non-compliance with the use of a particular category scheme, particularly one imposed from outside, or the adoption of an alternative are in this sense acts of resistance. (p.182)

And for management, the machine promises to tame and domesticate, to render rational and controllable the densely structured, heterogeneous texture of organizational life. ( $p$. 185)

She points towards the problematical nature of these categories: 
The assumption that "universal" distinctions such as requesting and promising are simple, however, conflates the simplicity of the category with the subtlety and complexity of the phenomenon categorized. (p. 185/6)

The performance of this particular reality excludes the performance of one where the interactional and contingent nature of speech is emphasised. A reality is performed where social identities are created in accordance with the predefined categories of intentions.

A second example: Christie (2008) discusses, within a postcolonial context, how the way databases (with their embedded ontologies) are developed and used to archive biodiversity has exclusionary and oppressive implications. His work is located among the Australian Aborigines for whom knowledge has a place-bound and narrative nature. The attempts by ethno-botanists to archive their knowledge by means of databases are in conflict with the ways they experience and perform the world. In the process Aboriginal knowledge is stripped of its meaning when ordered in the abstract categories of a database. Christie comments:

[T] here are two completely divergent knowledge traditions here interacting with the same subject matter. The knowledge traditions are at work in two worlds, the world of ethnobotanists who work to enlist traditional knowledge in conservation or development projects, and the world of indigenous people carrying on the ancestral task of making knowledge alive in the new generation, within the ancestral contexts of identity, ownership, custodianship, and accountability. Each has its own rules, structures and boundaries.

Christie points to the incompatibility of categories with references to fundamentally different ways in which plants are seen:

But plants, in Australian Aboriginal cultures, are not so much related to each other as
species, but to particular animals, or particular ancestors or clan groups or songs, or
ceremonial designs. How particular species of plants are related to each other is much less
relevant in Aboriginal knowledge work, than how they are related to the rest of the
sociomaterial world. Sometimes different stages in the lifecycle of a plant or animal, or
different genders, have their own names and complex networks of relatedness. The
flowers of a particular plant for example, may be related (as a 'calendar') to the
abundance of a particular food source (fish species, wild honey, or flying foxes) or
ceremonial time. It may also be related to a particular ancestral journey bestowing
particular rights over particular practices and resources to certain people. It has its value
through its extensive connections to people, places, events and entities outside of what
we know as the plant world.

While the database provides ethno-botanists with the means to capture and organise an increasing volume of data, it undermines the ability of the Aborigines in this case to continue with their narrative performance of place. The different heterogeneous performances of reality result in incompatible versions of reality that could become exclusionary and oppressive.

These analyses by Suchman and Christie reveal the ontological assumptions of the ISs and the ways in which they perform reality. These performances of reality promote partial interests and exclude others. By describing these particular performances the possibility is 
created to open up spaces of contestation. In Christie's case it led towards the development of alternative approaches to databasing. ${ }^{8}$

\section{Conclusion}

The ontologies embedded in databases and ISs are not neutral devices that simply represent an objective, pre-existing world or simply ensure efficient processes and procedures. They perform reality in intended and unintended political ways. The ontologies embedded in and emerging from ISs are powerful devices through which reality is performed in very particular ways. In order to make technology part of an overt democratic political process the ways in these reality-performing agencies function, should be made public. Such a shift in our understanding from a representational to a performative ontology opens up multiple terrains for the politics of contestation. These terrains have to be opened up whether ISs and ISOs see themselves in terms of realism, constructivism or instrumentalism. An ISO is never simply a representation of an existing reality, or simply a conceptual modelling and taxonomy - in all cases a particular reality is performed.

By showing that and how ISs and ISOs perform reality this article wanted to create an awareness of the necessity to open up spaces of contestation within areas that are regarded as mainly 'technical'. It developed a conception of technology as an agent within processes through which identities and relations are created and resources distributed. It has shown that this is the terrain, not only of the political but also of the ontological. Such an ontological politics does not only organise relations between people, but also constitutes reality itself. This powerful and mainly invisible work of technology should be made public.

This conception of the politics of technology goes further than attempts to make the design of technology more participatory since it recognises that new realities emerge through the heterogeneous practices of design and use. New approaches to design and use would follow once the contested nature of ontologies becomes public.

This article contributes to the opening up of terrains of contestation by discussing various examples of political ways in which IS are being developed and by highlighting the ontological performances.

\section{References}

Alcadipani, R. \& Hassard, J. (2010). Actor-Network Theory, organizations and critique. Towards a politics of organizing. Organization, 17(4), 419-435.

Austin, J. L. (1962). How to do things with words. Oxford: Oxford University Press.

Barad, K. (2007). Meeting the universe halfway. Quantum physics and the entanglement of matter and meaning. Durham, NC: Duke University Press.

Barry, A. (2001). Political machines: governing a technological society. London: Athlone Press.

Benhabib, S. (1996). Toward a deliberative model of democratic legitimacy. In S. Benhabib (Ed.), Democracy and difference. Contesting the boundaries of the political (pp. 67-94). Princeton, NJ: Princeton University Press.

\footnotetext{
${ }^{8}$ http://www.cdu.edu.au/centres/ik/ikhome.html
} 
Bennet, J. (2010). Vibrant matter: The political ecology of things. Durham, NC: Duke University Press.

Berg, M. (1998). The politics of technology: On bringing social theory into technological design. Science, Technology and Human Values, 23(4), 456-490.

Berg, M. (1999). Accumulating and coordinating: Occasions for information technologies in medical work. Computer Supported Cooperative Work, 8, 373-401.

Bijker, W. E. (2006). Why and how technology matters. In R. E. Goodin \& C. Tilly (Eds.), Oxford handbook of contextual political analysis (pp. 681-706). Oxford: Oxford University Press.

Bijker, W. E., Hughes, T. P. \& Pinch, T. (Eds.). (1987). The social construction of technological systems. Cambridge, MA: MIT Press.

Bloomfield, B. O. \& McLean, C. (1996). Madness and organization: Informed management and empowerment. In W.J. Orlikowski, G. Walsham, M.R. Jones Eं J.I. DeGross (eds.), Information Technology and Changes in Organization Work (pp. 371-392). London: Chapman \& Hall.

Bowker, G. C. (2000). Biodiversity, datadiversity. Social Studies of Science, 30(5), 643-683.

Bowker, G., Timmermans, S. \& Star, S. L. (1996). Infrastructure and organizational transformation: Classifying nurses' work. In W. J. Orlikowski, G. Walsham, M. R. Jones \& J. I. DeGross (Eds.), Information Technology and Changes in Organization Work (pp. 344-370). London: Chapman and Hall.

Butler, J. (1993). Bodies that matter. On the discursive limits of "sex." New York: Routledge.

Callon, M. \& Latour, B. (1981). Unscrewing the big Leviathan: how actors macro-structure reality and how sociologists help them to do so. In K. Knorr-Cetina \& A. V. Cicourel (Eds.), Advances in social theory and methodology: Toward an integration of micro- and macro-sociologies (pp. 277-303). Routledge and Kegan Paul.

Christie, M. (2008). Boundaries and accountabilities in computer-assisted etbnobotany. Retrieved 16 December 2012 from http://www.cdu.edu.au/centres/ik/pdf/EthnobotanySoftware.pdf.

Crutzen, P.J . \& Stoermer, E. . (2000). The “Anthropocene.” Global Change Nerwsletter, 41, $17-18$.

Fournier, V. \& Grey, C. (2000). At the critical moment: Conditions and prospects for critical management studies. Human Relations, 53(1), 7-32.

Gramsci, A. (2007). Prison notebooks, vol III. (A. Buttigieg, Ed. \& Trans.). New York: Columbia University Press.

Grey, C. \& Willmott, H. (2002). Contexts of critical management studies. Organization, 9, 411-418.

Habermas, J. (1984). The theory of communicative action, Vol. 1: Reasons and the rationalization of society. (T. McCarthy, Trans.). Boston: Beacon.

Hacking, I. (1983). Representing and intervening: Introductory topics in the philosophy of natural sciences. Cambridge: Cambridge University Press. 
Hacking, I. (2007). Kinds of people: Moving targets. Proceedings of the British Academy, 151, 285-318.

Howcroft, D. \& Wilson, M. (1999). Paradoxes of participatory design: The end-user perspective, paper presented at the critical management studies conference, $\begin{array}{lllll}\text { Manchester. } & \text { Retrieved } & 7 & \text { November } & 2010\end{array}$ http://www.mngt.waikato.ac.nz/ejrot/cmsconference/documents/information\%20tech /Howcroft.pdf).

Kroeze, J. H. (2012). Transdisciplinarity in IS: The next frontier in computing disciplines. Sprouts: Working Papers on Information Systems. Retrieved November 5, 2013, from http://sprouts.aisnet.org/12-2.

Latour, B. (1994). Where are the missing masses? The sociology of a few mundane artifacts. In W. E. Bijker \& J. Law (Eds.), Shaping technology / building society: studies in sociotechnical change (pp. 225-258). Cambridge: MIT Press.

Latour, B. (2002). Morality and technology. The ends of the means. Theory, Culture and Society, 19(5/6), 247-260.

Latour, B. (2004a). The politics of nature: How to bring the sciences into democracy. Cambridge, MA: Harvard University Press.

Latour, B. (2004b). Whose cosmos, which cosmopolitics? Common Knowledge, 10(1), 450462.

Law, J. (1986). On the methods of long-distance control: Vessels, navigation and the Portuguese route to India. In J. Law (Ed.), Power, action and belief (pp. 234 - 263). Routledge \& Kegan Paul.

Lyotard, J.-F. (1984). The postmodern condition. A report on knowledge. Manchester University Press. (G. Bennington \& B. Massumi, Trans.). Manchester: Manchester University Press.

Mol, A. (1999). Ontological politics. A word and some questions. In J. Law \& J. Hassard (Eds.), Actor-network theory and after. Oxford, UK: Blackwell.

Mol, A. (2002). The body multiple: Ontology in medical practice. Durham, NC: Duke University Press.

Mouffe, C. (1992). Democratic citizenship and the political community. In C. Mouffe (Ed.), Dimensions of radical democracy: Pluralism, citizenship, community (pp. 225-239). London: Verso.

Orlikowski, W. J. \& Iacona, C. S. (2001). Research commentary: desperately seeking the "IT" in IT research - a call to theorizing the IT artifact. Information Systems Research, 12(2), 121-134.

Scott, S. V. \& Wagner, E. L. (2003). Networks, negotiations, and new times: the implementation of enterprise resource planning into an academic administration. Information and Organization, 13(4), 285-313.

Smith, B. (2003). Ontology. In Blackwell Guide to the Philosophy of Computing and Information (pp. 155-166). Oxford: Blackwell.

Spicer, A., Alvesson, M. \& Kärreman, D. (2009). Critical performativity: The unfinished business of critical management studies. Human Relations, 62(4), 537-60. 
Suchman, L. (1994). Do categories have politics? The language/action perspective reconsidered. Computer Supported Cooperative Work, 2, 177-190.

Wand, Y. \& Weber, R. (1993). On the ontological expressiveness of information systems analysis and design grammars. Information Systems Journal, 3(4), 217-237.

Wand, Y. \& Weber, R. (2004). Reflection: Ontology in information systems. Journal of Database Management, 15(2), iii-vi.

Winner, L. (1986). The whale and the reactor. A search for limits in an age of high technology. Chicago: University of Chicago Press.

Winograd, T. \& Flores, F. (1987). Understanding computers and cognition. Reading, MA: Addison Wesley. 